\title{
Efficient Energy Performance within Smart Grid
}

\author{
Khizer Ayaz, Muhammad Sohail Sulemani, Naseer Ahmed \\ Department of Electrical Engineering, CIIT, Abbottabad, Pakistan \\ Email: Khizerayaz87@gmail.com
}

How to cite this paper: Ayaz, K., Sulemani, M.S. and Ahmed, N. (2017) Efficient Energy Performance within Smart Grid. Smart Grid and Renewable Energy, 8, 7586.

https://doi.org/10.4236/sgre.2017.83005

Received: December 26, 2016

Accepted: February 28, 2017

Published: March 3, 2017

Copyright (C) 2017 by authors and Scientific Research Publishing Inc. This work is licensed under the Creative Commons Attribution International License (CC BY 4.0).

http://creativecommons.org/licenses/by/4.0/

(c) (7) Open Access

\begin{abstract}
The Smart Grid, regarded as the next generation power grid, uses two-way flows of electricity and information to create a widely distributed automated energy delivery network. Energy/power plays a critical role for social, economic and industrial development. Because of industrial generalization, especially in agricultural and economical activities, the energy demand has increased rapidly in developed countries. Generation and usage of energy has direct impact on modern power grid. In this scenario energy management is a hard task because load is dynamic and we don't have control over it. Renewable or undepleted energy resources have great applications and impact in current electric power system situation. For example it gives pollution free (green) energy which is environment and user friendly. It is cost effective; it uses natural resources for its generation and hence do not waste any coal, gas etc. There are many inducements to empower energy productivity. As current smart grid is complex and non linear in operation and design, it used an optimized method that provides maximum efficiency with minimum input. Our work depicts a case study of hybrid electric aircraft for achieving high performance.
\end{abstract}

\section{Keywords}

Smart Grid (SG), Demand Response (DR), Renewable Energy,

Distributed Generators (DG)

\section{Introduction}

TRADITIONALLY, the term grid is used for an electricity system that may support all or some of the following four operations: Electricity generation, electricity transmission, electricity distribution, and electricity control. Energy/ power is a vital input for economic and industrial evolution [1]. The fast advancement of world economy, power needs rushed exceptionally, specifically among developing states. SG responds to wide ranging events and has a number of ca- 
tegorization due to its wide usage in various systems as smart electrical/power grid, sharp grid and imminent grid. SG is inducted in all energy power sources and in system of power and energy generations for optimum marketing, commerce and better management. The core prospect is to bring both the active customer participation and decision making at one grid and creating a working environment for both utilities and electricity users to address each other. DRPs in the Utility field enhance consistency via distributed generation or energy storage at substations, and overall giving the automated control to the grid [2]. SG measurement and verification resources work in a system of sensors, communications system, computer hardware and software. The software's enable monitoring, communication and analysis of the consumption of energy resource in the entire grid by comparing it with software data for gauging the performance of the resource. The energy resource has to be present in the entire grid during the process of measurement and verification [3]. Efficient energy management and distribution is empowered through DR. A series of devices function collectively with advanced software system for enabling DR. The software assets include AMI, communication systems, computerized building systems and complex devices. Measurement resources play an essential role of operating and running basic SG operations. These functions include automated meter reading and conveying cost signals. Validation, measurement and authentication are additional benefits and minimal amount is required for installation [4]. SG is a robust and efficient system that ensures reliability, efficiency, flexibility and delivers power in a controlled and smart way lowering peak demand. Investments are done in power sector to increase growth, development and to provide utility to consumers. By improving technology the grid will become a self-healing system and incorporating energy storage devices, renewable energy, and AMI and demand response programs will stabilize the grid. All these features of SG make grid resilient and suitable for existing energy demands and future needs.

\section{Description}

\subsection{Advanced Metering Infrastructure (AMI)}

AMI measures the quantity of energy used, analyzes how it is used by identifying the problems and reads the actual energy consumed by a consumer. AMI is considered the base of SG and enable consumers to use electricity more resourcefully and efficiently by informing consumers about detected problems on their systems [5]. Figure 1 describes the advantages of AMI. Automatic meter reading system differs from conventional meter. Automatic meter reading system is bidirectional and has various advanced features such as power theft applications, two way communications for real time data and has information regarding grid and user conditions. AMI comprises of smart meters and communication networks. The AMI system is connected to the management system, customer information displays and smart devices. Thirty percent reduction can occur in the demand during peak hours with the AMI in vogue. Installation of AMI improves consumption in a logical, economical and efficient manner [6]. 


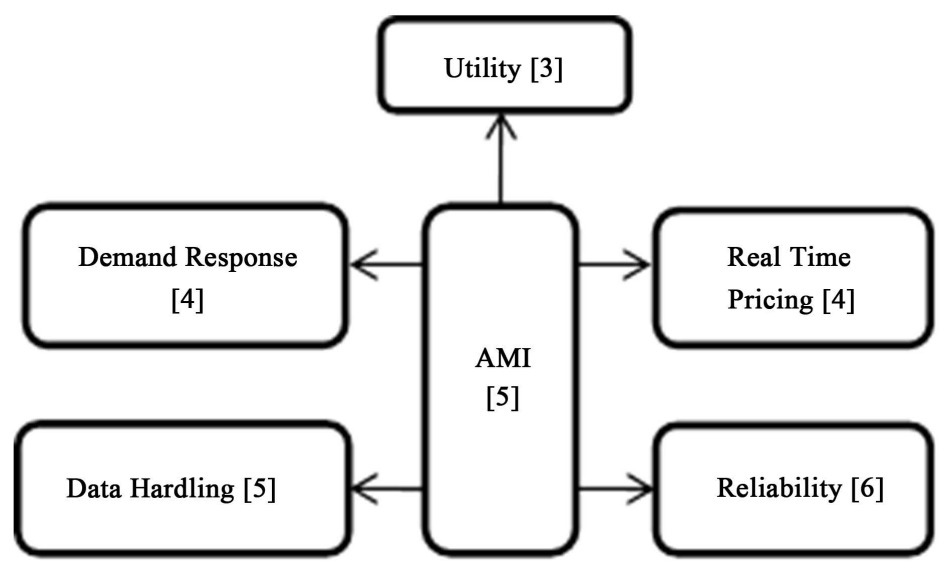

Figure 1. Advance Metering Interface (AMI).

\subsection{Integration of Renewable Energy into SG}

Demand of renewable has increased and 19 percent of the world electric energy share is of renewable energy out of which hydroelectric power makes 83 percent [8]. Shifting to renewable technology is necessary for green house security and to increase energy and resources security. As a result renewable energies and distributed generation are getting assistance and their stakes in electricity generation are increasing. Table 1 illustrates the benefits of renewable energy. The growing renewable production is the major concern for people working for development in SG system and the introduction of distributed generation to the electrical distribution system has been the key driver in the evolution of distributed system. However integration of renewables is not getting the desired market attention nor has participation in system management [9].

Renewable energy utilization in SG is increasing and supports the grid by improving power quality, reliability and reducing cost. Climate change has become a problem and to address this issue renewable energy resources are preferred and it provides grid stability [10].

\subsection{Demand Response Programs (DRPs)}

The DR enables the supply companies and authorities to have a firm control on the load and tariffs management which includes the control during peak hour of electricity demand and off demand periods. It simply gives the power supply authorities to shift energy consumption when the demand is high during peak hours of the day, to the off hours when the demand for electricity is the least. DR is implemented by two ways in vogue globally which includes direct load control or dynamic pricing [11]. Table 2 describes the characteristics of traditional DR and SGDR. In direct load control the main appliances at the consumers end are controlled by switching off and on at different times of peaks hours of electricity demand and leaner time of electric demand. The pricing techniques is implemented by enhancing the tariff charges during peak electricity demand hours in order to restrain the consumers to switch off high power consumption appliances in order to save high rates and same way to use them during leaner time of electric demand as the cost is very low [12]. 
Table 1. Advantages and disadvantages of renewable energy.

\begin{tabular}{cc}
\hline & Renewable Energy \\
\hline Advantages & Disadvantages \\
\hline Easily Regenerated [2] & Weather Dependency [7] \\
Boost Economic Growth [3] & High Installation Cost [8] \\
Easily Available [4] & Noise caused by Wind Energy [9] \\
Support Environment [5] & Fluctuation problem (Solar) [10] \\
Low Maintenance Cost [6] & Intermittency Issue (Wind) [11] \\
\hline
\end{tabular}

Table 2. Characteristics of traditional DR vs. SGDR [12].

\begin{tabular}{cc}
\hline Conventional DR & SGDR \\
\hline Controlled by Utility & Controlled by Customer \\
Interruptible Rates are Controlled & $\begin{array}{c}\text { All Available Loads are controlled } \\
\text { Equipment Provided by Market } \\
\text { Equipment is Provided by Utility }\end{array}$ \\
sR Products are Limited to Reliability & $\begin{array}{c}\text { DR products not limited includes Capacity, } \\
\text { Services Markets and load Management }\end{array}$ \\
Participation by Targeted, limited to residential & All Customers Participation \\
\hline
\end{tabular}

\subsection{System Operational Efficiencies}

SG applications are designed to provide efficient electricity service and it provides benefits to both consumer and utility. The benefits that result from these efficiencies include efficient real-time operations of electricity generation and additional services. Efficient use of capital investments for new infrastructures is done for the purpose of generation, transmission and distribution including efficient maintenance and administration. Since peak demands for electricity is quite higher than average level so SG should increase the consumption of assets. Asset utilization can assist in smoothing peak periods thus reducing the chances of emergency and producing electricity more efficiently. In distribution system SG technology can have considerable settlement to capital investments. DR schemes are synchronized with individual distribution feeders to lower peak loads thus controlling voltage efficiently [13] [14].

\subsection{Grid Modernization for Increasing Efficiency}

Modernization of grid includes up gradation of transmission and distribution ( $\mathrm{T}$ \& D) networks that extend electricity services to new population and develops the grid's productivity in supplying those services. The developing standards need to identify the global standards to enhance own capability for further adoption of these values to benefit the maximum and optimum level from the technology development, deployment and operations. Furthermore, development of a regulatory frame work is required to control and sustain SG investment by enabling sufficient economic returns for the electricity industry. For the purpose of shifting to SG a sustainable business models and a coordinated professional 
and industry approach is needed to safeguard investment in new technologies that help achieve the benefits of the smart grid. Effective consumer protection and engagement is the basic need which will escalate the consumers demand for SG technologies and ensure utility and for the consumer [15]. Figure 2 illustrates the characteristics of modernized grid and the relation of integrated information and communication technology with modernized grid.

\subsection{Concluding Remarks}

SG possesses huge catalogue due to its expanded usage in various systems and is considered to be the future grid. SG technology by now has gained the key role for a well synchronized energy distribution and is inducted in all energy power sources and in system of power and energy generations for prime marketing, commerce and better management. The emission of $\mathrm{CO} 2$ is the concern for greenhouse and the concept of EVs along with SG has addressed the problem. The integration of renewable sources will be the next point of consideration. Sustainability plays essential role in efficiency. Operations should be sustainable and focus should be on use of clean energy and a healthier environment. SG applications are intended to provide efficient electricity service and provide benefits to both consumer and utility.

\section{Challenges in Energy Efficiency Modeling}

Energy efficiency modeling is of great concern within the field of smart grid (SG). The SG implementation needs variety of improving constraints and challenges. Efficiency modeling is achieved by the implementation of optimization schemes. A massive information set is needed to assign totally different modeling techniques on the principle of various constraints and challenges rising inside the field of smart grid. The definition to the optimization is that the procedure adopted to implement totally different techniques for locating conditions to maximize the profit or in alternative words to reduce the price of whole process.

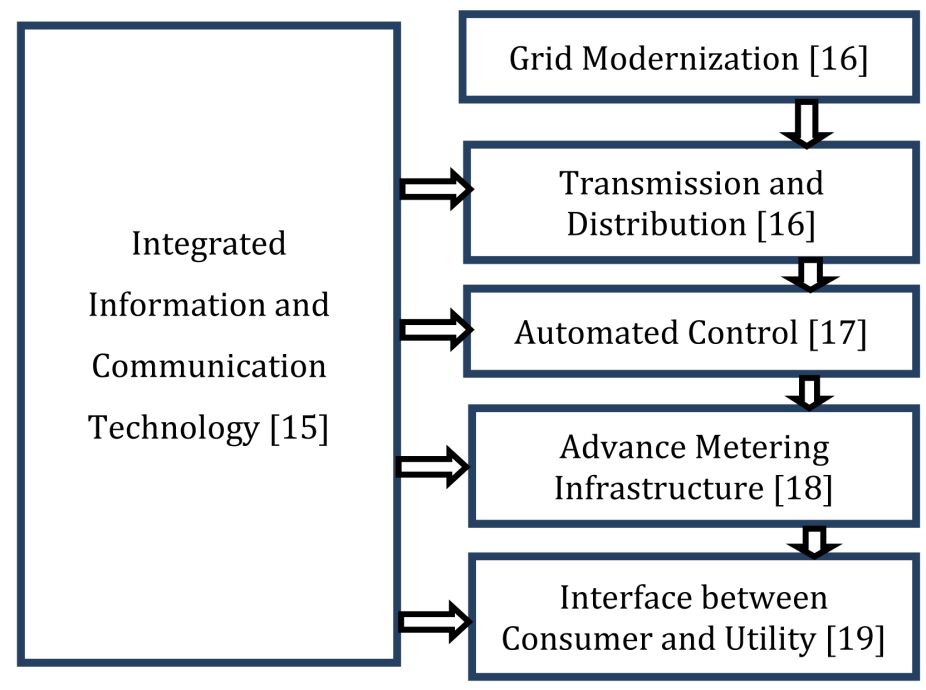

Figure 2. Characteristics of modernized grid. 


\section{- Communication Infrastructure Complexity}

The communication infrastructure of a SG is a system that is a combination of various systems and is very much complex. While modeling, analyzing and designing a communication infrastructure, a number of new challenges are required to meet. As a way to describe emerging behavior, the communication models that are being proposed are required to have the ability of accounting for uncertainty. The numeric tools used to solve very large scale problems must have the capability to perform analysis. As a fact the power system is a non-linear and very tightly coupled system [16] [17]. The communication infrastructure will be designed specifically to degrade control system and time required to manage elastic or graciously uncertainties and inconsistencies. The complexity of a SG communications infrastructure modeling challenges are encapsulated as: It is not possible to easily simulate electrical sub-system as it is tightly interconnected (Required to aid multi-physics approach) [18]. While considering various factors (power flow, control, and communications) different users are required to work at the same scenario (need to support multidisciplinary approach) [19].

\section{- DG Integration Challenges}

The integration of DG should be fastidiously investigated so as to attain optimum system performance. The DG integration could cause extra challenges in protection, reactive power management, and voltage fluctuation [19]. Moreover, the weather dependent nature of RER based DG raise the reliability concern of the system. Optimum system performance is achieved by careful investigation of DG integration. The DG is inserted within the area of enormous consumption the overloading conditions arise from low load density areas.

\section{Case Study}

Energy efficiency modeling is of great concern in the field of smart grid. Depending on the type of energy management strategy selected, the energy management system controls the power of each energy source devices through the reference signals (output voltage and maximum current). Efficient energy management and distribution is empowered through different program and their control. For efficient energy management and distribution DR is introduced. Sustainability plays essential role in efficiency. A case study is presented here for analysis of high energy efficiency performance. A hybrid electric aircraft model is implemented for analysis, results came from model are discuss briefly. Figure 3 presents a block diagram of hybrid aircraft model, implemented in MATLAB.

Model results are analyzed and discuss. Results include:

- Signal generator/ builder

- AC load stator current

- Electromagnetic and electrical torques

- Armature current

- Speed Characteristics

A signal generator/builder is an electronic device that generates repeating or non-repeating electronic signals in either the analog or the digital domain. It is 


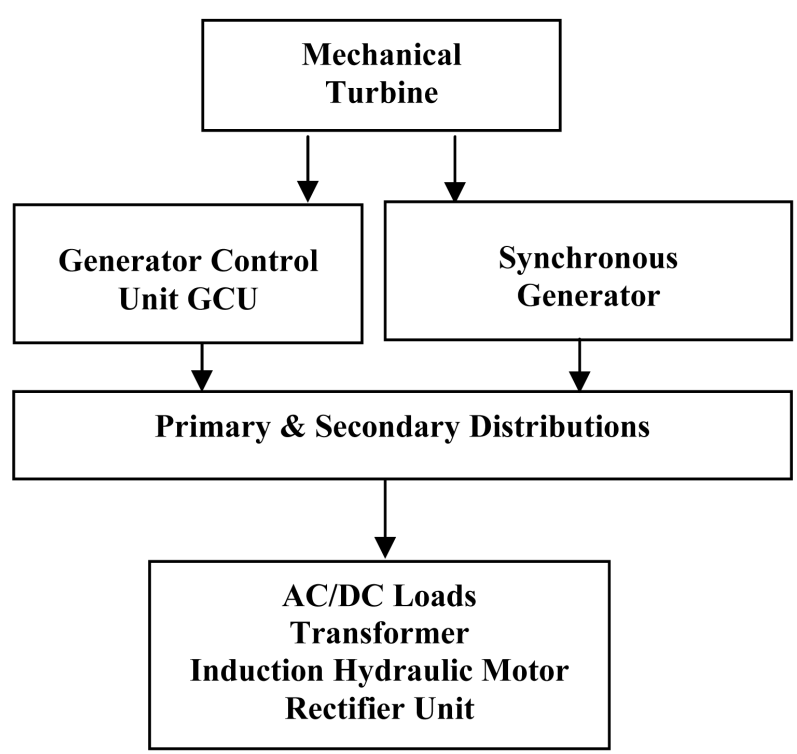

Figure 3. Block diagram of hybrid electric aircraft for high efficiency.

generally used in designing, testing, troubleshooting, and repairing electronic or electroacoustic devices, though it often has artistic uses as well.

There are many different types of signal generators with different purposes and applications and at varying levels of expense. These types include function generators, RF and microwave signal generators, pitch generators, arbitrary waveform generators, digital pattern generators and frequency generators. In general, no device is suitable for all possible applications.

Figure 4 represent power aircraft turbine signal. Signal magnitude varies with respect to time. At time 0, signal start from -5000 and grows linearly with time, at time $0.5 \mathrm{sec}$ signal magnitude is 12,000 and is stable up to $2 \mathrm{sec}$, after that it decays to 10,000 than suddenly increases to 20,000 . Signal magnitude varies because of dependency on too much factors and can be adjusted according to desired output.

A function generator is a device which produces simple repetitive waveforms. Such devices contain an electronic oscillator, a circuit that is capable of creating a repetitive waveform. (Modern devices may use digital signal processing to synthesize waveforms, followed by a digital to analog converter, or DAC, to produce an analog output). The most common waveform is a sine wave, but saw tooth, step (pulse), square, and triangular waveform oscillators are commonly available as are arbitrary waveform generators (AWGs). If the oscillator operates above the audio frequency range $(>20 \mathrm{kHz})$, the generator will often include some sort of modulation function such as amplitude modulation (AM), frequency modulation (FM), or phase modulation (PM) as well as a second oscillator that provides an audio frequency modulation waveform.

Figure 5 presents AC load stator current output. Initially form time 0 to $1 \mathrm{sec}$ output of AC load current is zero due to opposition of current in inductive load, current magnitude increases suddenly in interval 1 to 2.5. Behavior of current changes with respect to time as seen in figure, max peak of stator current occur 


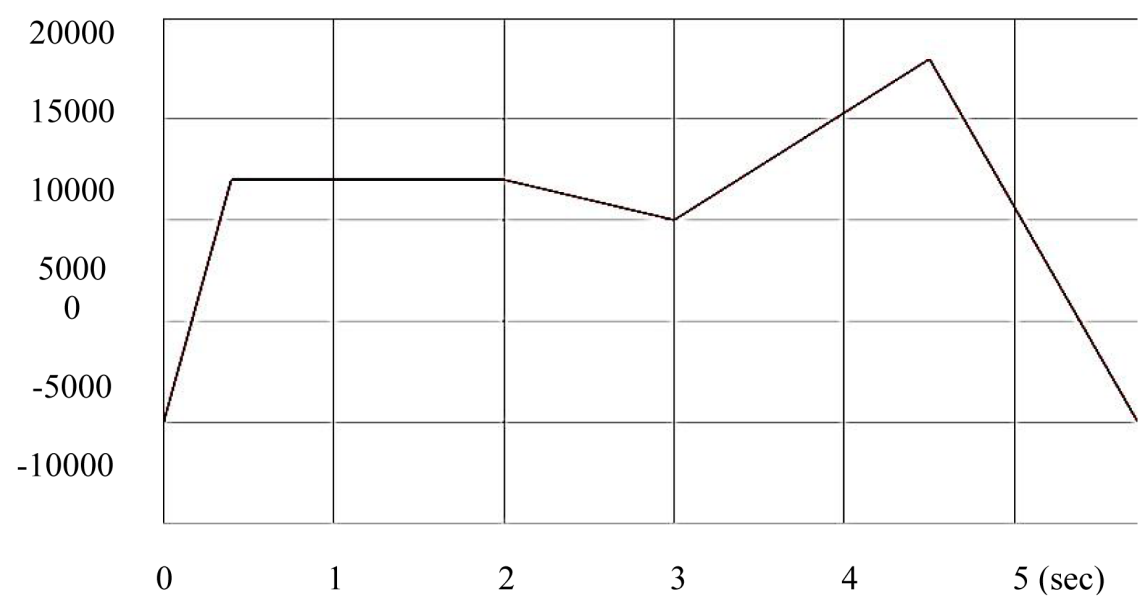

Figure 4. Signal generator for power aircraft distribution/mechanical engine (turbine).

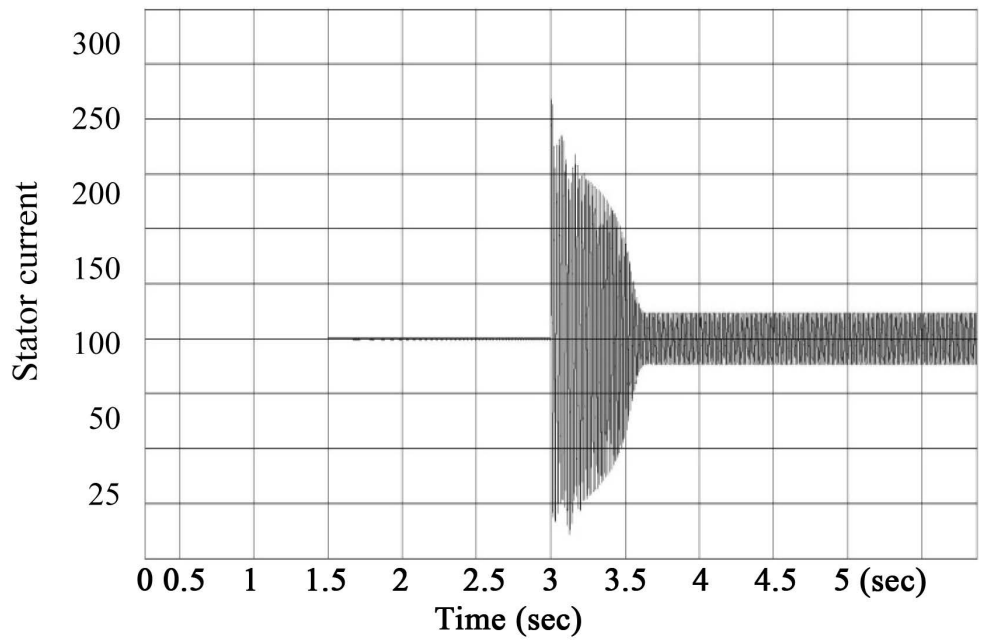

Figure 5. AC load (stator) current.

at 2.5 section. Graph depicts that too much ripples occur in various time intervals, they are mainly due to dynamic load behavior and parameters configuration during implementing mode.

Figure 6 presents AC load rotor speed characteristics curve. From time interval 0 to 2.5 output rotor speed is zero due to opposition of current in inductive load and their exist no rotating field in that interval, current magnitude increases suddenly in 2.5 to 3.5 interval, rotating magnetic field produces that tends rotor to rotate and its speed increases up to certain limit in current scenario. During interval 3.5 to 5 and onwards rotor speed stabilizes as continuous current supplied through source.

Figure 7 describes speed characteristic of one of the load of hybrid aircraft model for high energy efficiency. Time speed curve analysis can be made as for lighter load speed increases rapidly with increase in current. Speed become stabilized after sometime and reduces by reducing current. Speed also decreases if load burden increases. It can be analyzed from graph that at time interval 4 speeds is almost zero this is because of current reduction. 


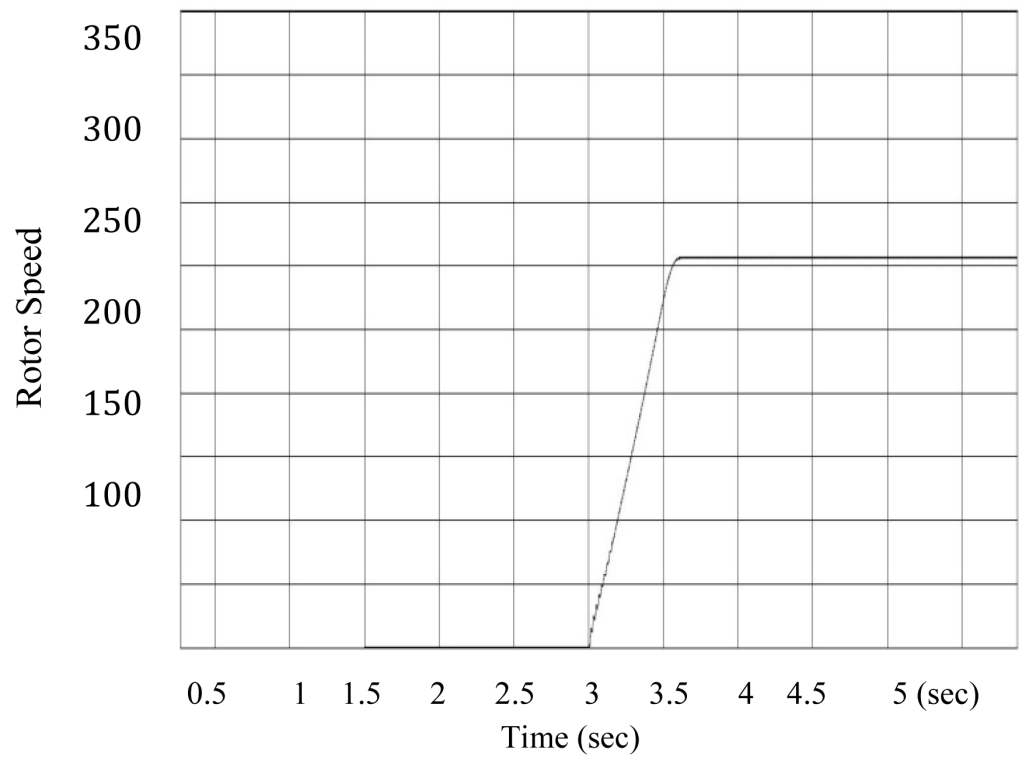

Figure 6. AC load (rotor) speed characteristics.

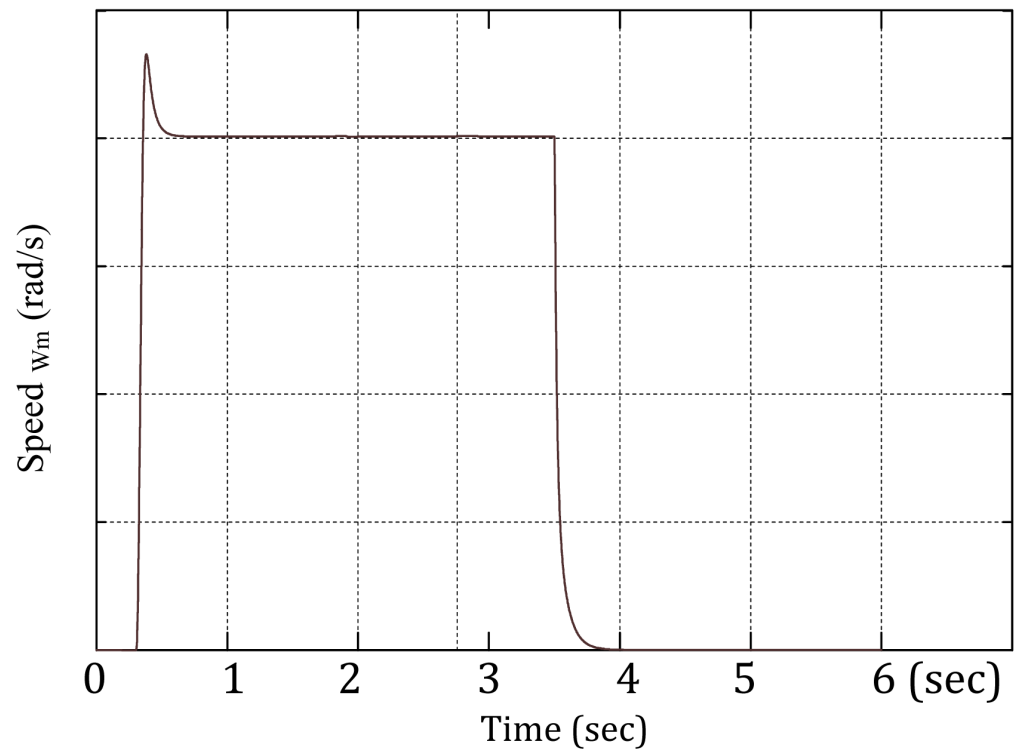

Figure 7. Output characteristic of load.

Figure 8 describes electrical torque characteristic curve. Initially there is a peak at start after that speed become stabilizes so far torque is. Torque curve is straight for some time and then decay because of current reduction. It can be analyzed from torque curve that it has dynamic response, for lighter load current drawn is more and speed become increase and vice versa for heavier load.

Figure 9 presents electromagnetic torque characteristic curve. Torque is zero initially between time interval 0 to 1 as there is no current flow and there exist no magnetic field. In interval 1 to 2.5 torque increases to certain limit as their exist a flow of current, torque curve decreases because magnitude of current decreases, a point will come when there is no flow of current and torque curve tends to zero. 


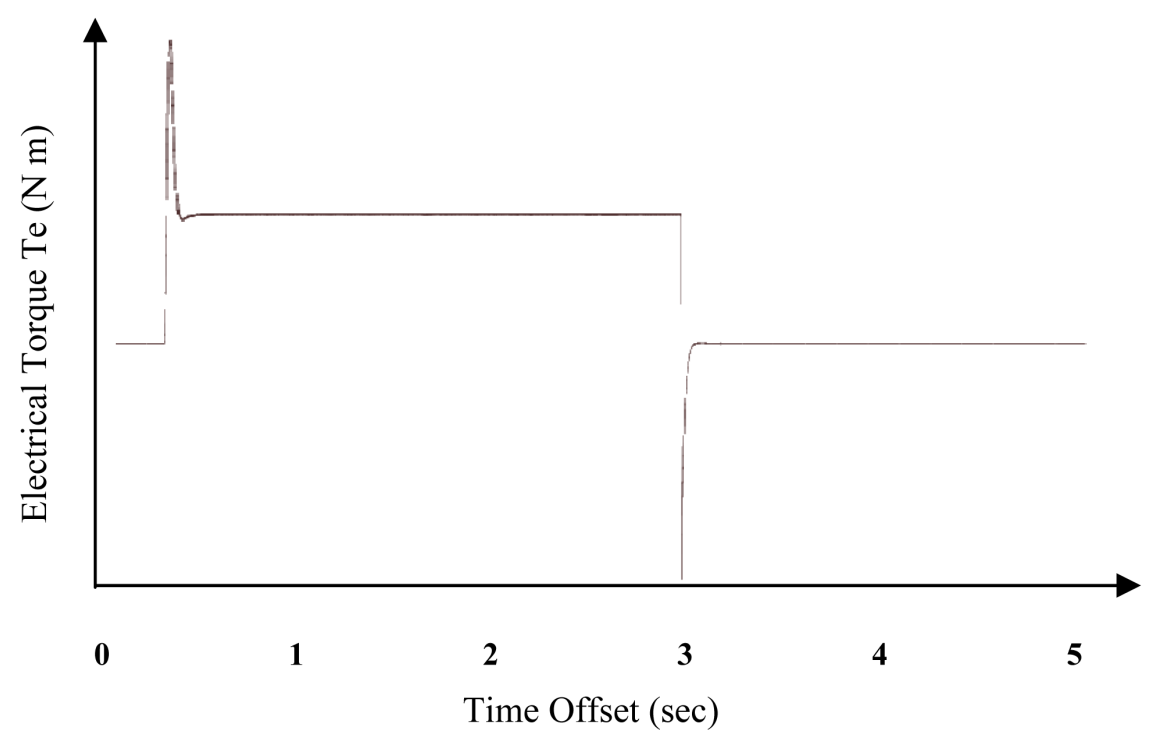

Figure 8. Electrical torque characteristic curve.

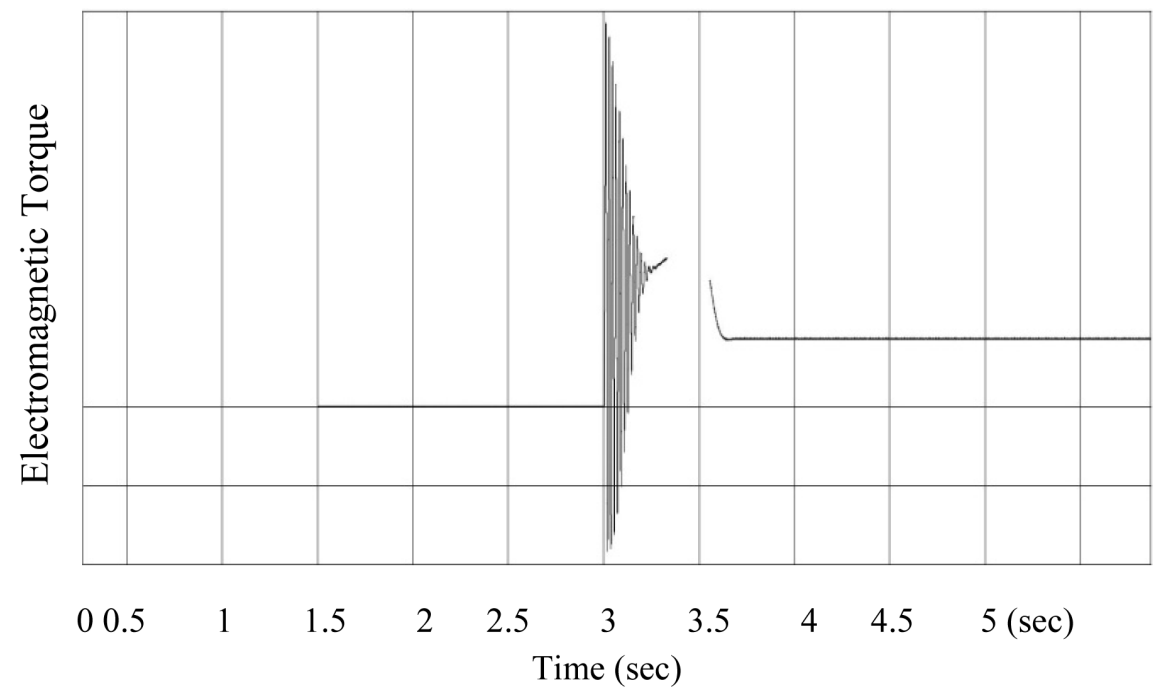

Figure 9. Output curve for electromagnetic torque.

\section{Conclusion and Future Work}

Efficient control of power systems is becoming increasingly difficult as they gain in complexity and size. Computerized power management system with fast and optimal communication network overcomes all major discrepancies of undue or inadequate load relief that were present in old conventional systems. This paper presents the basic perception, challenges and analysis of efficient energy performance within smart grid. Possible research direction that is essential to determine the control strategy potential for practical application is the utilization of more detailed system models both on the generation and load side. Generators can be more accurately represented by fifth or sixth order model that incorporate the effects of automatic generation control systems together with the influence of damper windings, armature voltage etc. On the other hand, the loads 
can be modeled as being voltage and frequency dependent instead of the passive constant impedance model used currently. All these questions will be a subject of our future research.

\section{Acknowledgements}

Authors are thankful to S. M. Ali for their fruitful comment and support throughout this paper.

\section{References}

[1] Vine, E. (2008) Breaking down the Silos: The Integration of Energy Efficiency, Renewable Energy, Demand Response and Climate Change. Energy Efficiency, 1, 4963. https://doi.org/10.1007/s12053-008-9004-Z

[2] Lee, T.-Y. and Chen, C.-L. (2009) Wind-Photovoltaic Capacity Coordination for a Time-of-Use Rate Industrial User. IET Renewable Power Generation, 3, 152-167. https://doi.org/10.1049/iet-rpg:20070068

[3] Martiskainen, M. and Coburn, J. (2010) The Role of Information and Communication Technologies (ICTs) in Household Energy Consumption/Prospects for the UK. Energy Efficiency, 4, 209-221. https://doi.org/10.1007/s12053-010-9094-2

[4] Zhou, W., Lou, C., Li, Z., Lu, L. and Yang, H. (2010) Current Status of Research on Optimum Sizing of Stand-Alone Hybrid Solar-Wind Power Generation Systems. Applied Energy, 87, 380-389. https://doi.org/10.1016/j.apenergy.2009.08.012

[5] Strupczewskim, A. (2003) Accident Risks in Nuclear-Power Plants. Applied Energy, 75, 79-86. https://doi.org/10.1016/S0306-2619(03)00021-7

[6] Skoglund, A., Leijon, M., Rehn, A., Lindahl, M. and Waters, R. (2010) Onthephysics of Power, Energy and Economics of Renewable Electric Energy Sources-Part II. Renewable Energy, 35, 1735-1740. https://doi.org/10.1016/j.renene.2009.08.031

[7] Evans, A., Strezov, V. and Evans, T.J. (2009) Assessment of Sustainability Indicators for Renewable Energy Technologies. Renewable and Sustainable Energy Reviews, 13, 1082-108. https://doi.org/10.1016/j.rser.2008.03.008

[8] Lund, H. (2007) Renewable Energy Strategies for Sustainable Development. Energy, 32, 912-919. https://doi.org/10.1016/j.energy.2006.10.017

[9] Hepbasli, A. (2008) A Key Review on Exergetic Analysis and Assessment of Renewable Energy Resources for a Sustainable Future. Renewable and Sustainable Energy Reviews, 12, 593-661. https://doi.org/10.1016/j.rser.2006.10.001

[10] Varun, Prakash, R. and BhatI, K. (2009) Energy, Economics and Environmental Impacts of Renewable Energy Systems. Renewable and Sustainable Energy Reviews, 13, 2716-3721. https://doi.org/10.1016/j.rser.2009.05.007

[11] Fan, Z., Kalogridis, G., Efthymiou, C., Sooriyabandara, M., Serizawa, M. and McGeehan, J. (2010) The New Frontier of Communications Research: Smart Grid and Smart Metering. Proceedings of the 1st International Conference on EnergyEfficient Computing and Networking, Passau, 13-15 April 2010, 115-118. https://doi.org/10.1145/1791314.1791331

[12] Woodruff, S.L. (2004) Complexity in Power Systems and Consequences for Real-Time Computing. IEEE PES Power Systems Conference and Exposition, New York, 10-13 October 2004, 1770-1775. https://doi.org/10.1109/psce.2004.1397733

[13] Moslehi, K. and Kumar, R. (2010) Smart Grid-A Reliability Perspective in Innovative Smart Grid Technologies (ISGT 2010). 1-8. 
[14] Soroudi, A., Ehsan, M. and Zareipour, H. (2011) A Practical Eco-Environmental Distribution Network Planning Model Including Fuel Cells and Non-Renewable Distributed Energy Resources. Renewable Energy, 36, 179-188. https://doi.org/10.1016/j.renene.2010.06.019

[15] Kahraman, C., Kaya, I. and Cebi, S. (2009) A Comparative Analysis for Multiattribute Selection among Renewable Energy Alternatives Using Fuzzy Axiomatic Design and Fuzzy Analytic Hierarchy Process. Energy, 34, 1603-1616. https://doi.org/10.1016/j.energy.2009.07.008

[16] Connolly, D., Lund, H., Mathiesen, B.V. and Leahy, M. (2010) A Review of Computer Tools for Analyzing the Integration of Renewable Energy into Various Energy Systems. Applied Energy, 87, 1059-1082. https://doi.org/10.1016/j.apenergy.2009.09.026

[17] Sadegheih, A. (2010) A Novel Formulation of Carbone Missions Costs for Optimalde Sign Configuration of System Transmission Planning. Renewable Energy, 35, 1091-1097. https://doi.org/10.1016/j.renene.2009.10.011

[18] Fang, X., Misra, S., Xue, G. and Yang, D. (2012) Smart Grid-The New and Improved Power Grid: A Survey. IEEE Communications Surveys \& Tutorials, 14, 944-980. https://doi.org/10.1109/SURV.2011.101911.00087

[19] Phuangpornpitak, N. and Tia, S. (2013) Opportunities and Challenges of Integrating Renewable Energy in System. Energy Procedia, 34, 282-290. https://doi.org/10.1016/j.egypro.2013.06.756

\section{Submit or recommend next manuscript to SCIRP and we will provide best service for you:}

Accepting pre-submission inquiries through Email, Facebook, LinkedIn, Twitter, etc. A wide selection of journals (inclusive of 9 subjects, more than 200 journals)

Providing 24-hour high-quality service

User-friendly online submission system

Fair and swift peer-review system

Efficient typesetting and proofreading procedure

Display of the result of downloads and visits, as well as the number of cited articles

Maximum dissemination of your research work

Submit your manuscript at: http://papersubmission.scirp.org/

Or contact sgre@scirp.org 